\title{
INFLUENCE OF END CONTSRAINS ON THE GLOBAL BEHAVIOUR OF A BOX GIRDER
}

\author{
Daniela Mihaela Boca $^{\mathrm{a}, *}$, A. Faur ${ }^{\mathrm{a}}$, A. Boca \\ ${ }^{a}$ Technical University of Cluj-Napoca, Faculty of Civil Engineering, 15 C. Daicoviciu Str., 400020, Cluj-Napoca, Romania
}

Received: 23.02.2016 / Accepted: 03.03.2016 / Revised: 18.05.2016 / Available online: 31.05.2016

DOI: 10.1515/jaes-2016-0001

KEY WORDS: precast/prestressed concrete, box girders, end constrains, numerical analysis

\begin{abstract}
:
This study aims to presents the importance of end constrains, boundary conditions and position of the applied forces regarding the design of precast/prestressed concrete box girders. The study is based on a destructive test which was performed on a $37.1 \mathrm{~m}$ span single-cell prestressed concrete box girder. The scope of the test was to certify the usage of such girders for the new Transylvania motorway bridges. The test is numerically reproduced through a full 3D FEM model implemented in SAP2000. The influence of the end diaphragms is considered by analysing the beam's behaviour to six loading conditions: one of which is replicating the loadings during the test, while the others are conceived as real vertical and horizontally loading scenarios. The results obtained for the girders with and without end constrains are compared. The performances of both design solutions in the presence of prestressing are highlighted where applicable. It is considered that the results of this study may provide very important data if considering that Romania has an urgent need to realize a modern and an adequate transport infrastructure.
\end{abstract}

\section{INTRODUCTION}

In recent years, precast, prestressed concrete beams have been produced for highway bridges with significantly higher spans than in the past (Stratford, 1999). For example, in UK, the bridge standards established a maximum span length of $40 \mathrm{~m}$, while spans of up to $55 \mathrm{~m}$ are commonly accepted in Canada. If spans get longer or the beams are becoming more slender, complex mechanical phenomenon can appear, such as: stability problems, short and long term deflections, deformations depending on the position of the loading, the prestressing force affecting the behaviour of the beams, etc. These phenomenon can affect in a certain degree all types of beams, regardless of their cross-section shape: T, I, Box, Y, Super Y(SY). Choosing the most efficient cross-section depends on the factors that affect the general and the local behaviour of the girder. All these aspects are given in specific standards for each country. A box girder normally can be made of prestressed concrete, structural steel or steel reinforced concrete.

\footnotetext{
* Corresponding author, e-mail: Daniela.BOCA@bmt.utcluj.ro
}

The closed cross-section shape called "box" offers a higher torsional stiffness resistance in comparison with an open crosssection. However, box girders still contain complex structural problems which may be neglected by the common design regulations. One consistent summary of the more representative research performed on Box Girder Bridges is offered by Sennah and Kennedy (Sennah, 2002). The concerning on the behaviour of straight and curved box-girders starts with the development of the curved beam theory by Saint-Venant in 1843 and the development of thin-walled beam theory by Vlasov in 1965 . These two basic theories mark the birth of all research efforts published to date on the analysis and design of straight and curved box-girder bridges (Chirag, 2014). Starting with this, technical papers, reports, and books were published in the literature, concerning a right development of the box-girders. Attempts for modifying the two theories, but also experimental and analytical studies were made. The main scope of the developed research was focused on several areas of interest: how to make box girder bridges more stable; how to increase strength and rigidity; how to achieve slender sections to reduce material costs; how to modify the shape of the hollow box 
cross-section for a better loading path, etc. (Maisel, 1970; Maisel, 1973; Bridge Design Manual, 2001; Lark, 2004; Robertson, 2005).

The study of Kaneko and Mihashi (Kaneko, 1996) determined that the cracking transition is induced by changes of the boundary conditions. Ishac and Smith (Ishac, 1985) confirmed the efficiency and fairness prediction of SAP2000 regarding the deflected shape of a box girders viaduct. The short-term deflections and the bending strains measured during a load test on the viaduct were successfully predicted using a threedimensional numerical model and adequate boundary conditions. Zhi-Qi He and Liu (Zhi-Qi He, 2010) proposed an optimal three-dimensional strut-and-tie model for the anchorage diaphragm and developed direct equations to facilitate the design.

As regarding the present study, the Pujayo viaduct numerical model (Ramos, 2010) was used as a starting point for the development of the 3D SAP2000 analysis.

\section{SCOPE OF WORK}

The purpose of this study is to show the end diaphragm influence upon prestressed box girders when subjected to different loading scenarios. The structural behaviour is examined by comparing the deformed shapes and stress distribution of two numerical models which were analysed using SAP2000 (Computers \& Structures Inc, 2015) computer program. The results highlight the differences in behaviour between the two design solutions (i.e. with and without end diaphragms), and helps defining supplementary recommendations for improving the analysis procedure.

\section{SPECIMEN DESCRIPTION AND LOADING CONDITIONS}

\subsection{Test PC box girder design specifications}

The study is based on the largest destructive test ever performed in Romania (Păstrav, 2011). The specimen consisted in a full scale PC (i.e. prestressed concrete) prefabricated bridge box girder $(2.45 \times 3.28 \times 37.10 \mathrm{~m})$, manufactured by Bechtel International Inc. Reno-Nevada, Cluj-Napoca (see Figure 1). The box girder was designed in accordance with the technical specifications offered by Iptana SA Bucharest $\left({ }^{*} *\right.$ Referat, 2008).

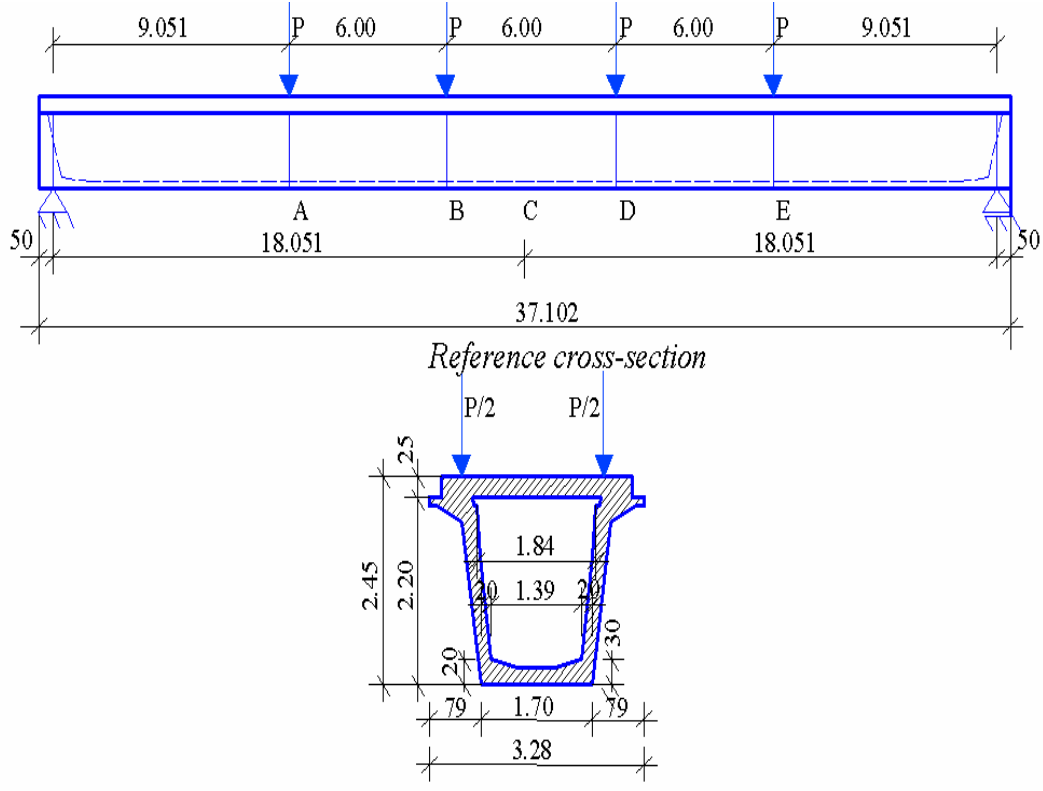

Figure 1. Static Scheme (Mircea, 2009) 
The model used in this study was tested between 15-18 of September and 2008 and it was subjected to 6 loadingunloading cycles. The PC box girder is composed by a $\mathrm{U}$ shape prefabricated unit and a top slab of $25 \mathrm{~cm}$ thickness made of cast in situ concrete. The results following the testing procedure are used for the proposed numerical model of the box girder. The static scheme and the loading conditions are given in Figure 1. The total height of the transversal sections is $2.45 \mathrm{~m}$, the precast $U$ girder and the top concrete slab having $2.20 \mathrm{~m}$ in height and $0.25 \mathrm{~m}$ in thickness, respectively. As it can be seen below, the bottom flange thickness varies along the beam's span.

The design concrete classes were $\mathrm{C} 35 / 45$ for the precast $\mathrm{U}$ unit and $\mathrm{C} 25 / 30$ for the top cast in situ slab. The effective cube strength of concrete at 28 days considered in the test was $f_{c, \text { cube }}=50.0 \mathrm{MPa}$ (i.e. corresponds to a cylinder strength $f_{c, c i l}=38.5 \mathrm{MPa}$ ) for the prefab U unit, and $f_{c, \text { cube }}=41.0 \mathrm{MPa}$ (i.e. $\left.f_{c, c i l}=32.3 \mathrm{MPa}\right)$ in the top slab.

The control prestressing stress was $1440.0 \mathrm{MPa}$. Prestressing was introduced through 84 strands T $15.2 \mathrm{~mm}$ positioned on the tensioned area of the girder, and 4 strands $\mathrm{T} 6.35 \mathrm{~mm}$ placed in the compressed area, as seen in Figure 2. Passive longitudinal and shear reinforcement was made of high ductility steel, with the yielding strength $f_{y}=255.0 \mathrm{MPa}$, yielding strain $\varepsilon_{y}=1.21 \%$, tensile strength of $318.8 \mathrm{MPa}$ and its associated elongation of $20 \%$. Thereby, the prestressed strands were made of high strength prestressing steel of low relaxation class, having the yield stress $f_{p y}=1636.0 \mathrm{MPa}$ and the tensile strength $f_{p u}=1860.0$ $\mathrm{MPa}$ with its associated strain $2 \%$. The transfer of the prestressing forces to the concrete was designed for a minimum concrete strength $f_{c i, c u b e}=41.5 \mathrm{MPa}$. The reinforcement and the tendons are positioned in the moddeling in the same manner as in the real life experiment.

\subsection{End constraints and boundary conditions}

The box girder described above is used for the first numerical model. Both ends are stiffened with end diaphragms having approximately $50 \mathrm{~cm}$ thickness. The girder is simply supported at both ends (i.e. the rotational degrees of freedom are released), but the supporting devices are located at the bottom of the cross-section and not at the centroid.

As for the second numerical model, the same box girder is used, but having the end diaphragms removed. Therefore, the girder's ends are completely unstiffened. However, the supporting conditions are identical for the two models, the second being relevant for bridges designed as through boxes (i.e. car, train or pedestrian traffic is ensured through the interior of the box girders).

\subsection{Loading scenarios}

The first loading condition reproduces the position and the characteristics of the test loads. Four concentrated loads are applied on both models. The forces are positioned on the top of the girder, as represented in Figure 1. The behaviour at cyclic loading is not referred in this study, although the test was performed for multiple loading-unloading sequences (Mircea, 2009). In the present case, the external forces are considered to vary only monotonically, starting from zero until the maximum force is reached.

The serviceability load $\mathrm{P}_{\text {serv }}=256.4 \mathrm{kN}$, the cracking load

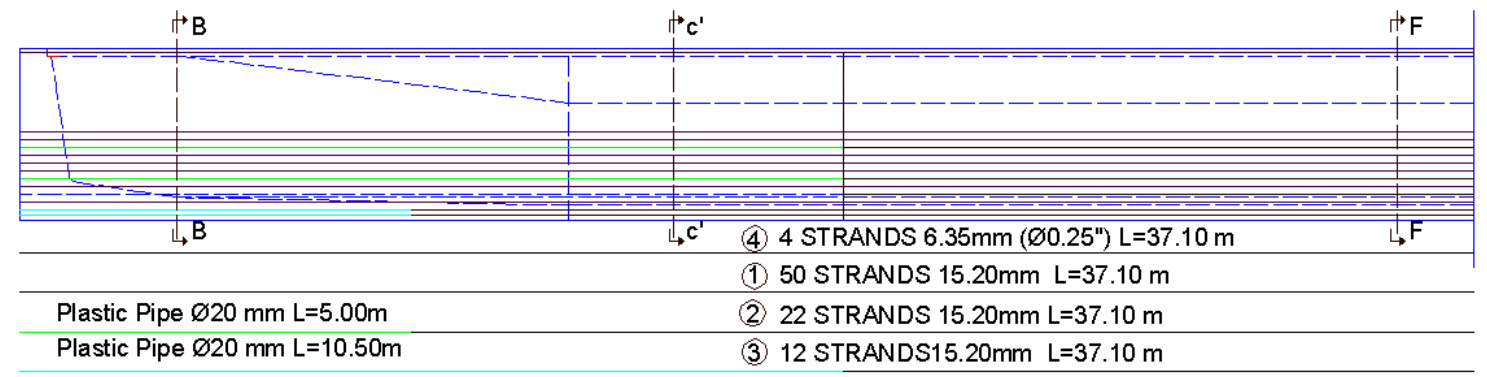

Section B-B

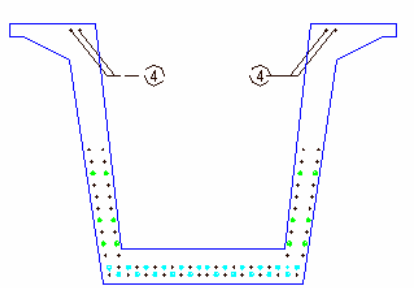

Section $C^{\prime}-C^{\prime}$

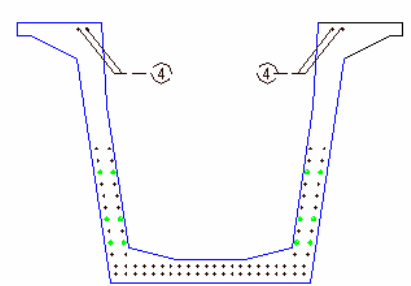

Section F-F

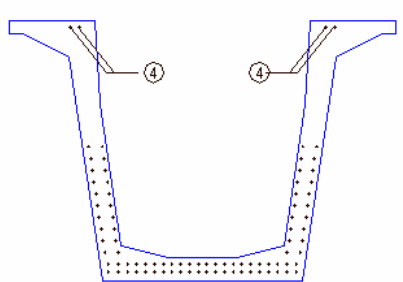

Debonded strands on $\mathrm{l}=10.50 \mathrm{~m}$

Debonded strands on $\mathrm{l}=5 \mathrm{~m}$

+ Bonded strands

Figure 2. Prestressing strands location 


\section{3D MODELING OF THE BOX GIRDER}

$\mathrm{P}_{\text {crack }}=482.80 \mathrm{kN}$ (i.e. related to the Serviceability Limit States which corresponds to a limit crack width of $0.1 \mathrm{~mm}$ ) and the failure load $\mathrm{P}_{\text {failure }}=1490.76 \mathrm{kN}$ were obtained during the test (Mircea, 2009; Referat, 2008). All three load levels are compared with the forces resulted following the computer analysis.

Five additional loading cases were considered in order to study the influence of the loading type and position referred to the cross-section. The loads are applied as in the study performed by Ishac and Smith (Ishac, 1985), but the values are scaled in order to reach the total cracking load which was measured during the test (i.e. total cracking load equals $4 \times \mathrm{P}_{\text {crack }} \cong 1931$ $\mathrm{kN})$. The position of the applied forces and their scaled values are presented in Figure 3 and Table 1 .

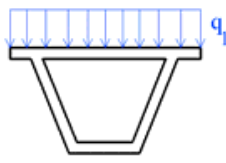

Case 1

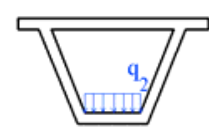

Case 2

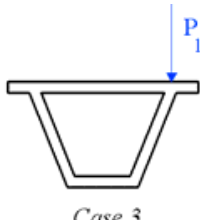

Case 3

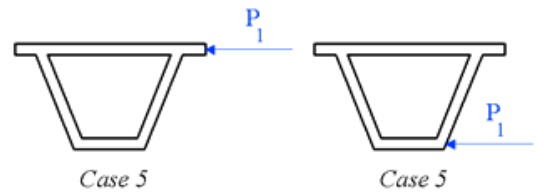

Figure 3. Loading cases

For Case 1 and Case 2, a uniform distributed load $\left(\mathrm{q}_{1}\right.$ and $\mathrm{q}_{2}$, respectively) is applied on the upper and lower flange, respectively, both representing a symmetric component of live load. The load on the lower flange represents the live load on a through box, according to (Păstrav, 2011). Regarding the third case (i.e. Case 3), $P_{1}$ is a vertical concentrated load and represents an antisymmetric component of the live load. In Case 4 and Case 5 the load $P_{1}$ is a horizontal force/ which is applied at the upper and lower flanges, as shown in Figure 3.

Case 1 and Case 2 represents the symmetric vertical loading where the beam is free of twist, and Cases 3-5 corresponds to asymmetric vertical loading and to horizontal where the governing behaviour of beam involves twisting and distortion. The values of the loadings for each case are given in the Table 1.

\begin{tabular}{|c|c|}
\hline Case of loading & Loading value \\
\hline Case 1 & $\mathrm{q}_{1}=15.80 \mathrm{kN} / \mathrm{m}^{2}$ \\
\hline Case 2 & $\mathrm{q}_{2}=34.70 \mathrm{kN} / \mathrm{m}^{2}$ \\
\hline Case 3 & $\mathrm{q}_{3}=50.50 \mathrm{kN} / \mathrm{m}^{2}$ \\
\hline Case 4 & $\mathrm{q}_{4}=50.50 \mathrm{kN} / \mathrm{m}^{2}$ \\
\hline Case 5 & $\mathrm{q}_{5}=50.50 \mathrm{kN} / \mathrm{m}^{2}$ \\
\hline
\end{tabular}

Table 1. Loading cases

\subsection{Finite element models}

Both 3D FEM models were constructed in SAP2000 computer program using layered shell and tendon elements (Computers \& Structures Inc, 2015). Figure 4 and Figure 5 detail the analysis model.

The layered shell elements were adopted in order to capture the nonlinear behaviour of the RC (i.e. reinforced concrete) walls from which the girder is made of. Five layers representing the concrete and the reinforcement are used for all the shell elements. The concrete cover and the concrete core are modelled through one single layer, while the top and bottom reinforcement are modelled with four layers oriented in two orthogonal directions. The material nonlinearity is introduced by using the unconfined Mander constitutive model (Mander, 1988) for the concrete and a simple bilinear model with hardening for the reinforcement. The same material properties were used as those obtained during the test. The maximum shell element dimensions after discretization are restricted to $0.25 \mathrm{~m}$. The discretised box girder can be seen in Figure 4.

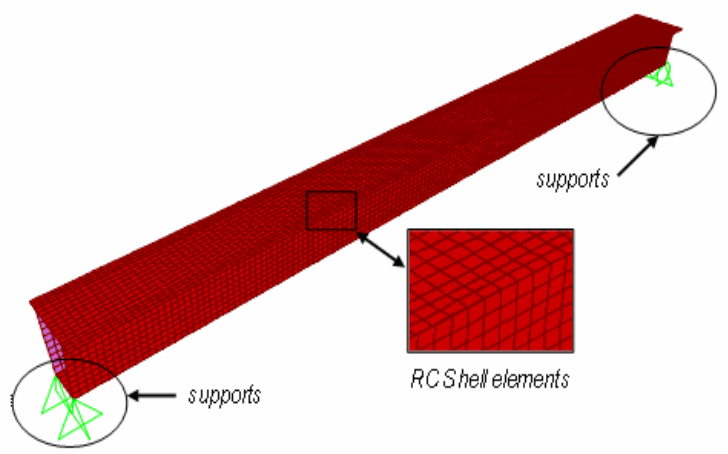

Figure 4. RC shell elements used for the 3D FEM model

The prestressing is introduces through tendon elements. All 88 strands (i.e. 84 strands T $15.2 \mathrm{~mm}$ and 4 strands T $6.35 \mathrm{~mm}$ ) are placed in groups of 2, 3 and 4 tendons, for an easier implementation. The material nonlinearity is captured by using a simple bilinear constitutive model for the prestressing steel. All the prestressing losses during the test were assumed to be somewhere between $15 \%$ and $20 \%$, and a prestressing loss of $20 \%$ is therefore introduced for the tendon elements as a conservative measurement. The debonding is modelled by controlling the discretization. The debonded region of the strand is modelled as a single tendon element, while the bonded region is discretized into multiple elements having the same length as the surrounding shell elements. The tendon elements placement is presented in Figure 5. 
器

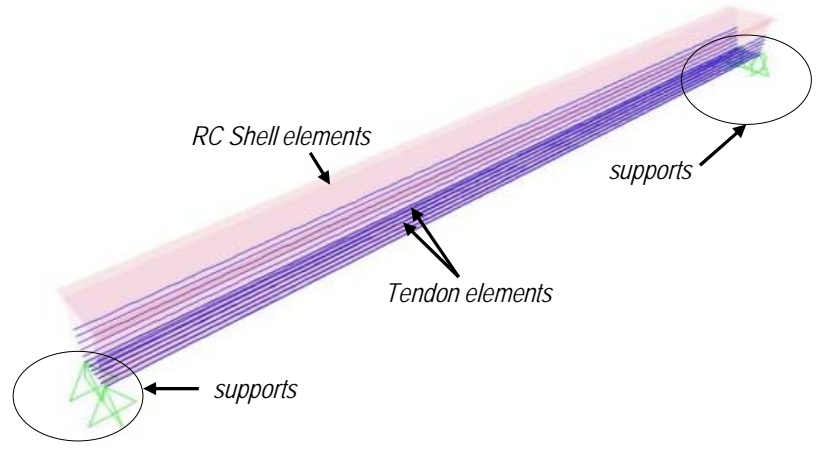

Figure 5. Tendon elements used for the 3D FEM model

The supports are placed at the bottom flange (see Figure 1, Figure 4 and Figure 5) as in the experiment. The end diaphragms are modelled with diaphragm constrains which causes all of its joints to move together as a planar diaphragm that is rigid against membrane deformation (Computers \& Structures Inc, 2015). No end constrains are used for the second model where the end diaphragms are eliminated.

\subsection{Load cases for the analysis}

All the six analysis cases (i.e. the test loading case and the five additional loading cases that are numerically analysed) are static nonlinear cases. The first analysis case is displacement controlled, while the other five are force controlled. The initial conditions for all the six analysis cases represent the stressstrain state after transferring the prestressing force to the concrete. Therefore, this initial state is captured through an analysis case which includes the self-weight load and the prestressing induced by the tendons.

\section{ANALYSIS RESULTS}

\subsection{Comparison with the full-scale experiment}

The model having end diaphragms must be compared in terms of force-displacement values with the test results in order to verify the numerical analysis. Therefore, the force-displacement curve was obtained following the nonlinear analysis. Because it is a displacement controlled procedure, the maximum imposed displacement at the centre of the girder was $80 \mathrm{~mm}$. Due to the long runtime and given that $\mathrm{L} / 500$ equals $74.2 \mathrm{~mm}$, the analysis has been deliberately stopped at approximately $65.5 \mathrm{~mm}$. The total force which corresponds to this displacement is 4233.765 $\mathrm{kN}$, being with $29 \%$ lower than the total failure load reached during the test (i.e. total failure load equals $4 \times \mathrm{P}_{\text {failure }} \cong 5963$ $\mathrm{kN})$. The reached total load is 4.13 times higher than the total serviceability load and 2.19 times higher than the total cracking load. All these values are represented in Figure 6.

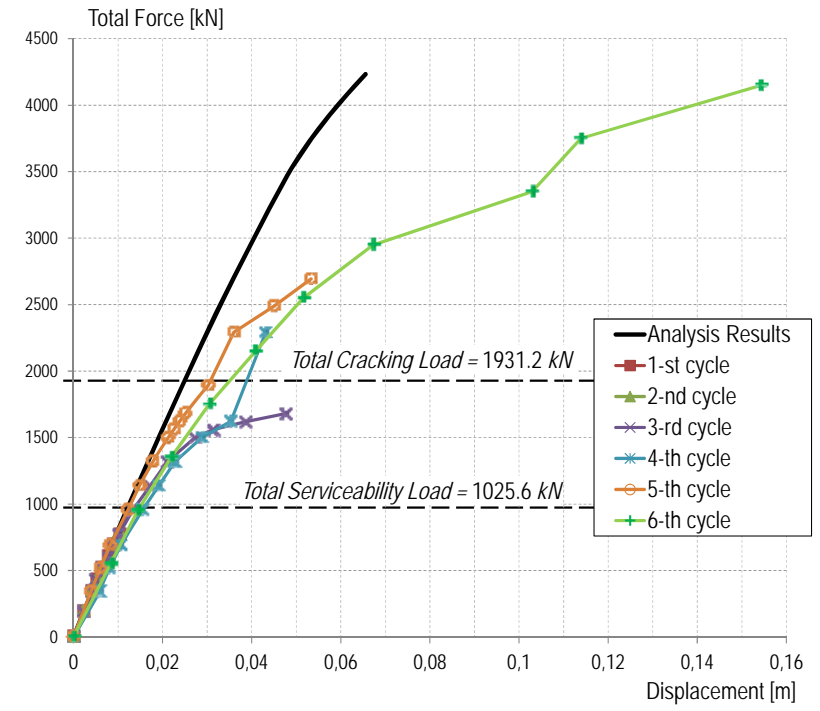

Figure 6. Force-displacement curves comparison

The force-displacement curve obtained following the analysis is compared with the test curves. These are presented in Figure 6. Only the loading branches of the loading-unloading cycles were compared with the resulted curve. The unloading branches obtained during the test were ignored.

As it can be seen from Figure 6, the analysis results are very close to the test results if the imposed load is lower than the serviceability load. Above this value and until the cracking load is reached, the differences are getting more pronounced, but without exceeding differences larger than $100 \%$. One interesting fact is that the 3-rd cycle loading branch has the largest displacement, while the 5-th cycle loading branch has the lowest displacement. The difference between the displacement obtained from the analysis and the loading branch of the last cycle at cracking load is approximately $10 \mathrm{~mm}$, while at maximum load, the difference is more than twice (i.e. the displacement measured during the test is 2.36 times larger than the maximum displacement reached through the numerical analysis).

The more pronounced nonlinear behaviour observed at the experiment can be explained through the softening effect which occurs in materials when cyclic loadings are applied. Therefore, the above comparison is more relevant bellow the cracking limit.

\subsection{The influence of end diaphragms at test loads}

The influence of the end diaphragm upon the behaviour of the box girder can be identified if the results of the two models (i.e. the models with and without end diaphragms) are compared. The resulted force-displacement curves are identical and their graphical representation is presented in Figure 7. Therefore, the stress distribution associated with the initial and the final deformed states have to be compared. The stresses in the concrete core are presented starting from Figure 8 to Figure 11. 
DE GRUYTER
OPEN

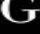

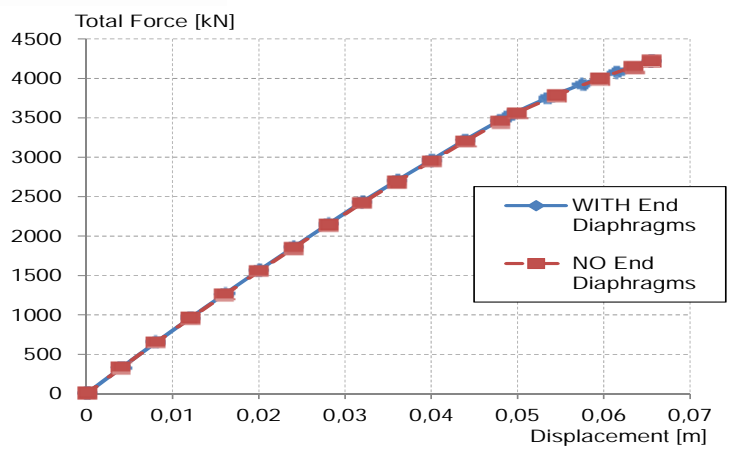

Figure 7. The force-displacement curve of the two models

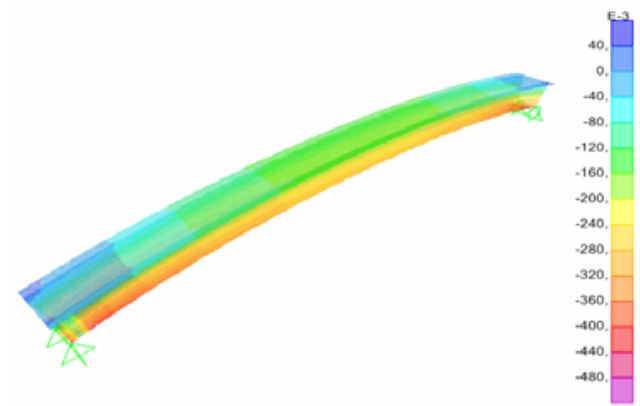

Figure 8. Stress distribution of the concrete core for the initial state with end diaphragms

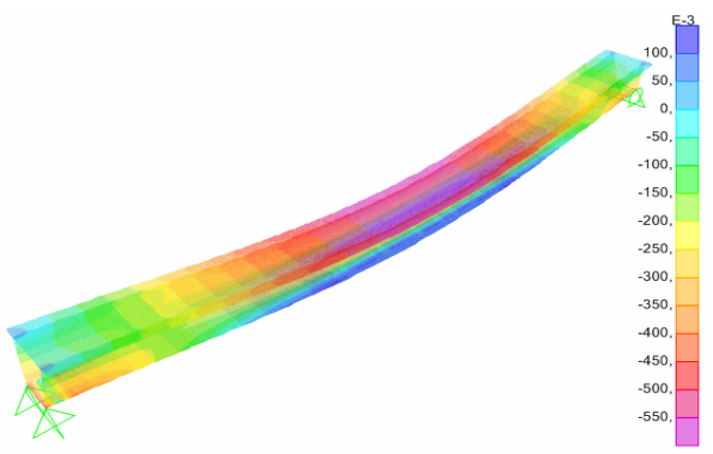

Figure 9. Stress distribution of the concrete core for the final state with end diaphragms

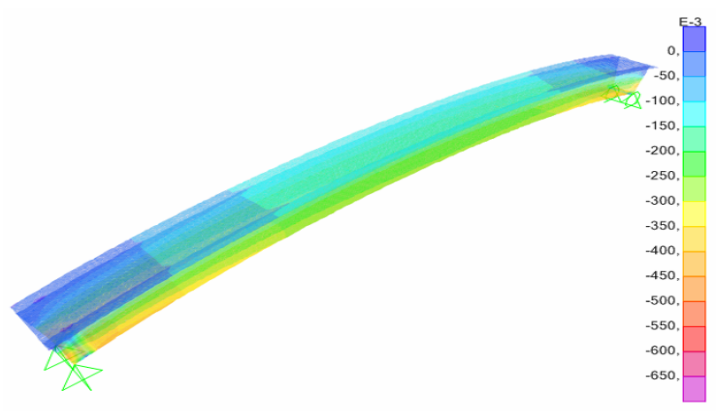

Figure 10. Stress distribution of the concrete core for the initial state without end diaphragms

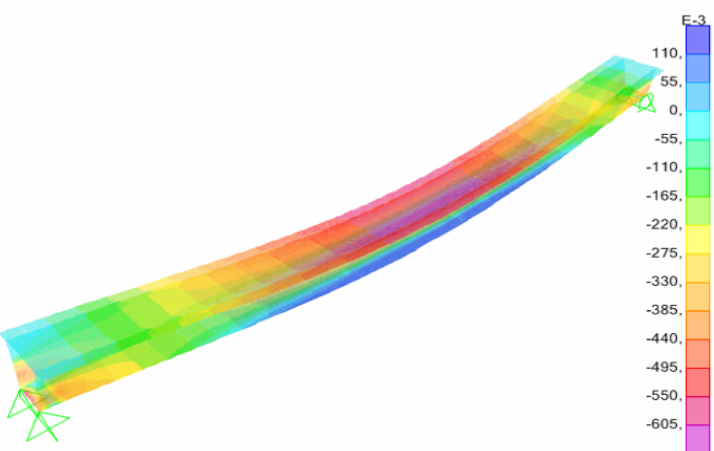

Figure 11. Stress distribution of the concrete core for the final state without end diaphragms

Very small stress differences appear in the concrete core between the two models. The values from Figure 8 to Figure 11 are normalized by material strength. It can be seen that in the final stress state, the tension in the concrete core reaches $0.1 \times f_{c, \text { cil }}$ for the model with end diaphragms and $0.11 \times f_{c, \text { cil }}$ for the model without end diaphragms. Cracks due to tension in the bottom flange are very likely to occur at these levels of stress. No cracks due to crushing of the concrete core can be identified, because the maximum compression stress does not exceeds $0.65 \times f_{c, \text { cil }}$. There should be mentioned that almost no tension appears in the initial states. Almost the same stress distribution can be identified for both models, which explains the similarity between the two force-displacement curves (see Figure 7).

\subsection{The influence of end diaphragms at different loading scenarios}

Both models have been analysed to the five loading scenarios mentioned by Ishac and Smith (Ishac, 1985) and adapted for the current situation. All the performed analysis are static nonlinear. The loading forces from Table 1 were reached in all cases and the displacement curves along the three orthogonal axes were obtained. The displacements were measured at the bottom flange, in the same cross-section locations as the concentrated forces that were applied during the test (see Figure 1). The results are presented in the following figures:

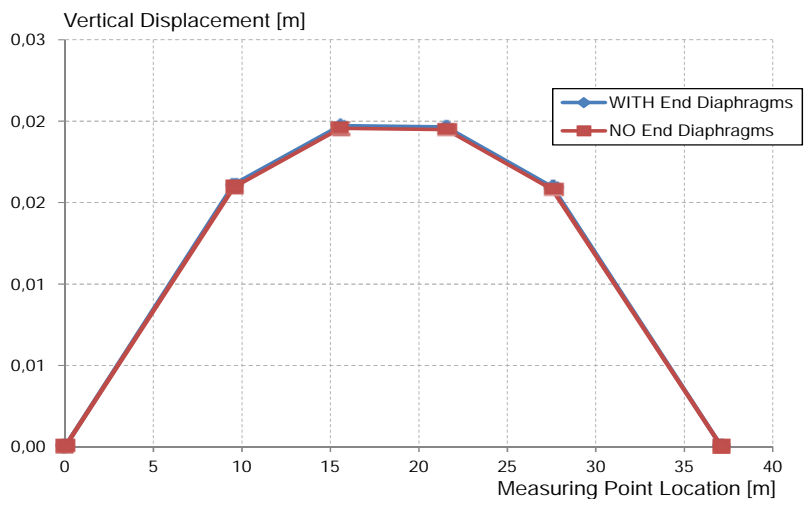

Figure 12. Case 1 and Case 2 vertical displacements 


\section{DE GRUYTER}

G

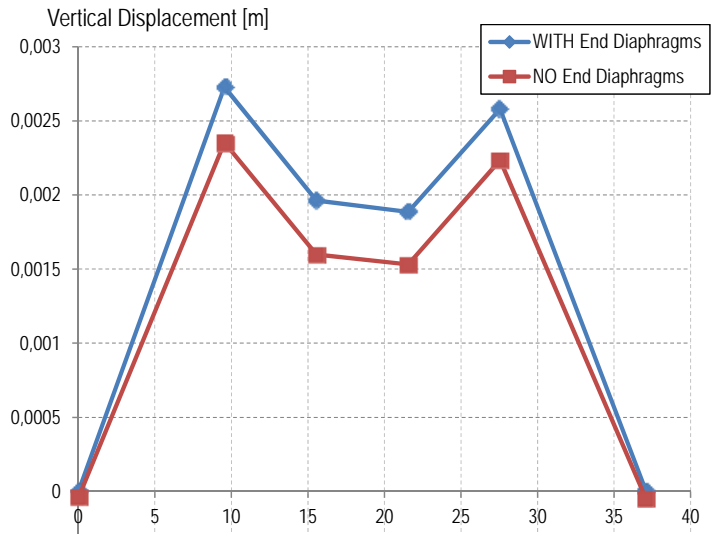
$-0,0005$

Measuring Point Location [m]

Figure 13. Case 3 vertical displacements

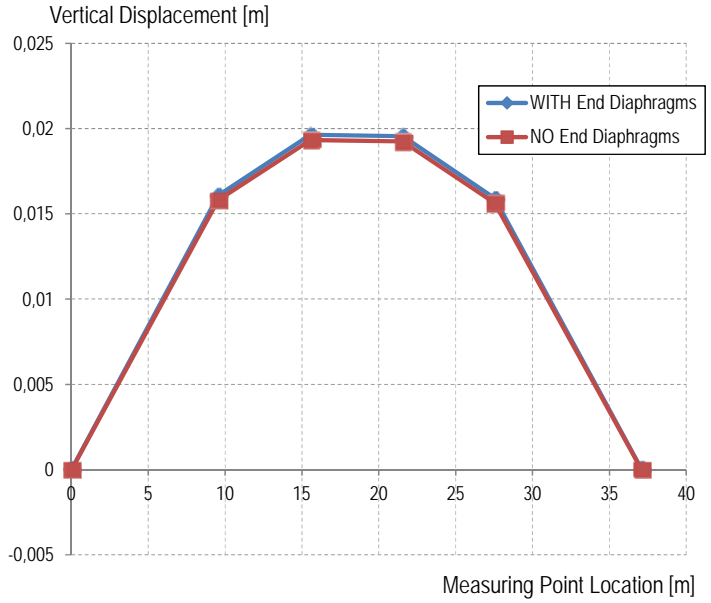

Figure 14. Case 4 and Case 5 vertical displacements Vertical Displacement [m]

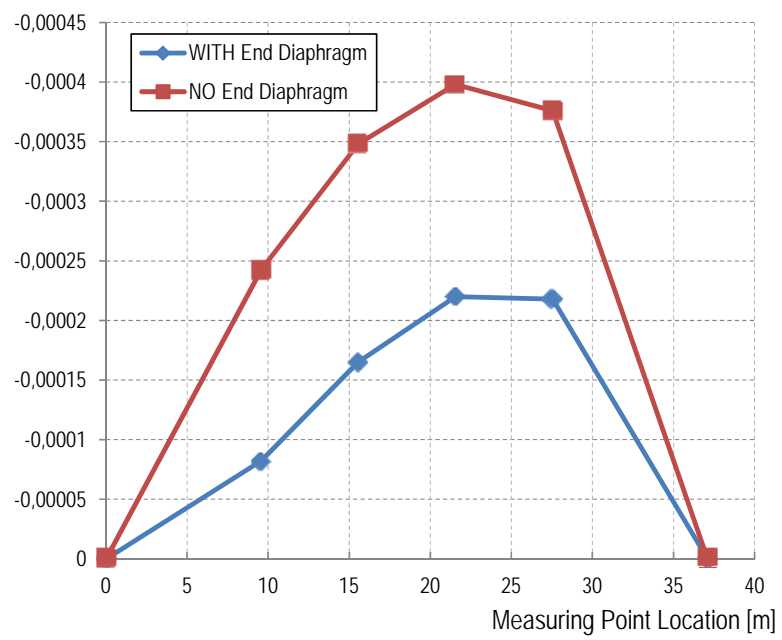

Figure 15. Case 1 and Case 2 lateral displacements

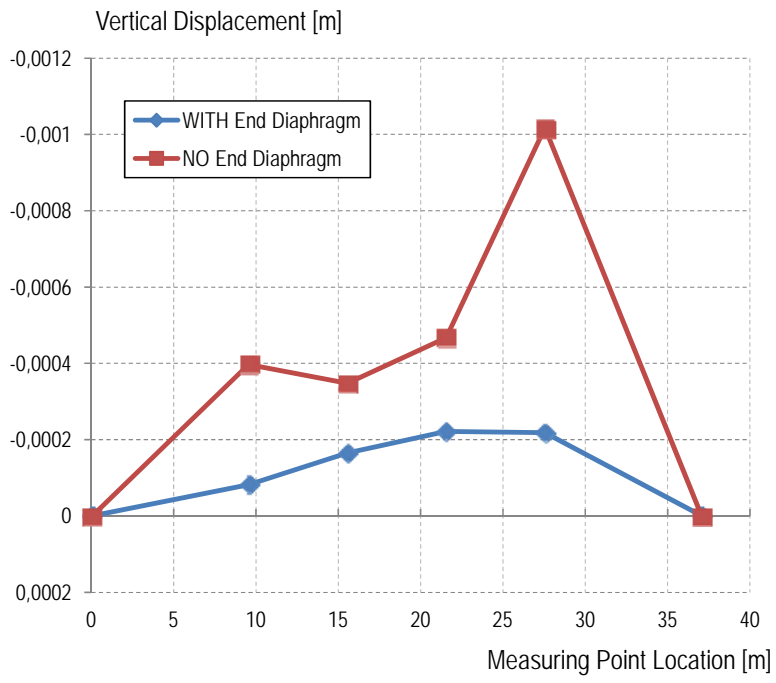

Figure 16. Case 3 lateral displacements

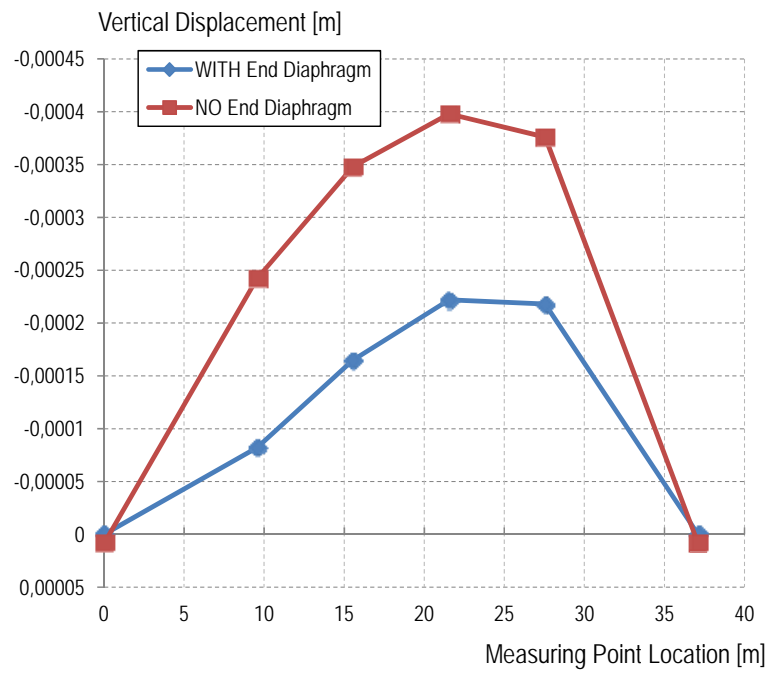

Figure 17. Case 4 and Case 5 lateral displacements

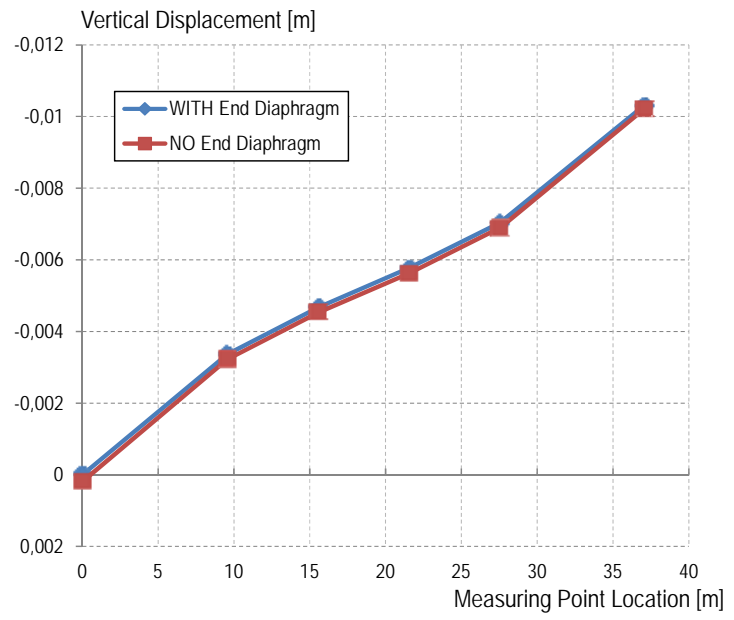

Figure 18. Case 1 and Case 2 longitudinal displacements 
DE GRUYTER
OPEN

G

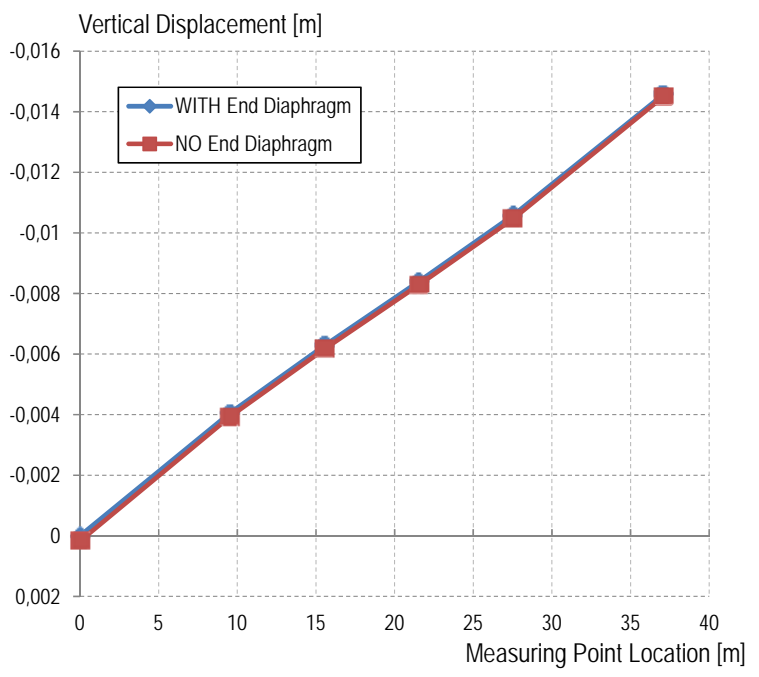

Figure 19. Case 3 longitudinal displacements

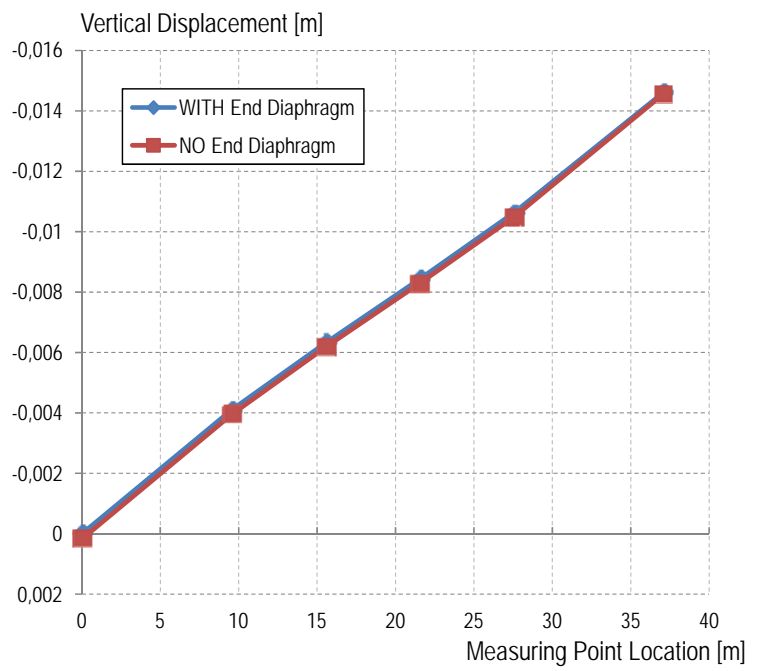

Figure 20. Case 4 and Case 5 longitudinal displacements

The vertical and longitudinal displacement curves almost coincide for both numerical models, except for the vertical displacement curved obtained from loading Case 3. Moreover, identical curves were obtained for loading Cases 1 and 2 on one hand, and for loading Cases 4 and 5 on the other hand. This states that the position of the external forces (i.e. at the top or at the bottom flange) doesn't influence the behaviour of the box girder, regardless of whether the beam is provided with or without end diaphragms. These statements apply for external forces which are lower than the cracking load.

Significand differences are observed when comparing the lateral displacements instead. Even if the position of the external forces does not influence the overall behaviour (i.e. the same curves were obtained for the loading Cases 1 and 2, and for the loading Cases 4 and 5), the latera displacements obtained for the model with no end constraints are almost twice as higher as the displacements obtained in the presence of end diaphragms. However these displacements are very small compared with the beam's length and can be neglected (see Figure 15 and Figure 17). The displacements generated by analysing the third loading case clearly highlight the presence of twisting and distortion effects. The later ones are more pronounced if no end diaphragms are provided. Therefore, even if the lateral displacements values are small, a more detailed comparison is needed for a better investigation of the cracking state.

\subsection{Concrete core stress state for loading Case 3}

The maximum principal stresses in the concrete core for the third loading case are presented in Figure 21 and Figure 22.

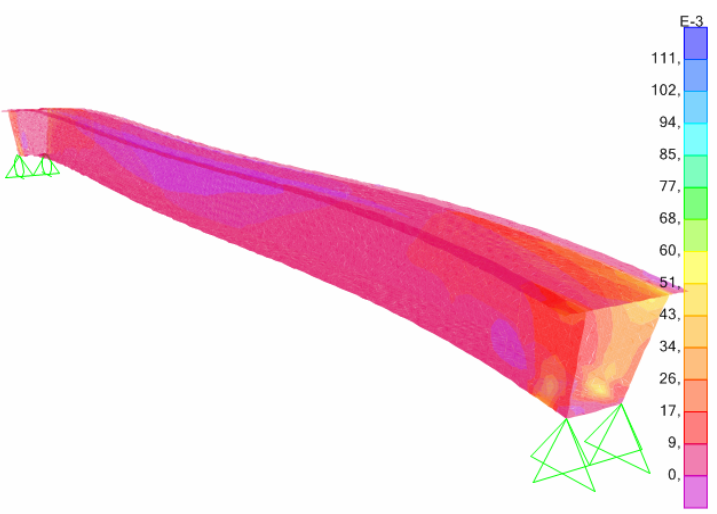

Figure 21. Principal stress distribution of the concrete core for the numerical model with end diaphragms

By analysing the results, it can be seen that cracking due to tension may occur in both cases. The maximum stress for the model having end diaphragms is $0.111 \times f_{c, \text { cil }}$, while the maximum stress for the model with no end diaphragms is $0.18 \times f_{c, \text { cil }}$. This implies that the asymmetric vertical load causes high stress values, leading to possible residual damages if large cracks are developing into the concrete core.

The stresses obtained for the third case are comparable with the stresses encountered for a maximum total vertical force which is two times higher (see Figure 6).

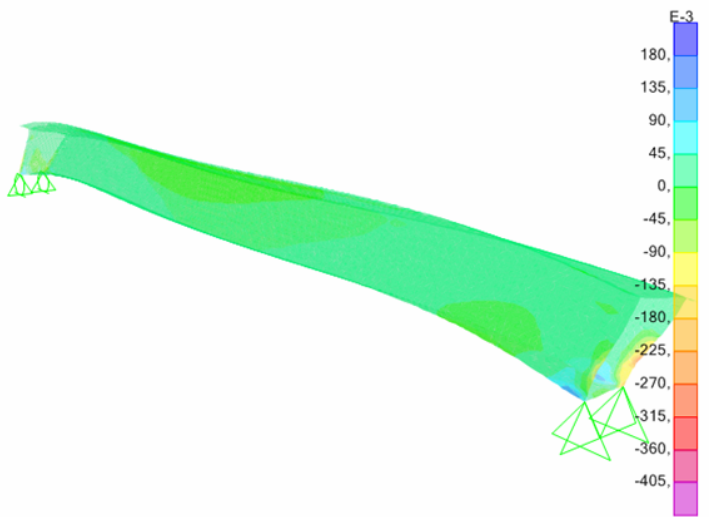

Figure 22. Principal stress distribution of the concrete core for the numerical model without end diaphragms 


\section{CONCLUSIONS}

During the presented study, two numerical models were constructed through the use of SAP2000 computer program. The influence of end diaphragms upon the behaviour of a PC box girder was captured by performing computer analysis for six loading cases: one reproducing a full-scale experiment, and 5 cases under which the type and the loading positioning have been varied.

The results showed that if symmetrical loads are applied, then the influence of the end diaphragms can be neglected. Moreover, the end diaphragm influence can be neglected even for lateral loads, regardless the external load positioning.

On the other side, if the applied loads are asymmetrical, then special care should be taken in design, because excessive cracking may occur. The stresses can become very large even for box girders that are provided with end diaphragms. Therefore, if twisting and distortion effects are likely to appear, than the design should be performed on 3D FEM models, regardless of whether the box girder is provided or not with end diaphragms.

\section{REFERENCES}

Bridge Design Manual, (2001), Texas Department of Transportation (August 2001).

Chirag Garg, M., Siva Kumar, M. V., N., 2014. Prestressed Tendons System In A Box Girder Bridge, International Journal Of Civil Engineering (Ijce) 3(3), pp. 1-8.

Computers \& Structures Inc., 2015. CSI Analysis Reference Manual For SAP2000®, ETABS $\AA$, and SAFE. Web page address: https://www.csiamerica.com/products/sap2000.

Ishac, I., Smith, T., (1985). Approximations for Moments in Box Girders, Journal of Structural Engineering, Volume 111, Issue 11 (November 1985), Elsevier Engineering Structures 27 (2005), 1820-1827.

Kaneko, Y., Mihashi. H. (1996). Analytical study on the crack transition of concrete shear key. Mater Struct 1999;32(3):196202.

Lark, R. J., Howells, R.W., Barr BIG, 2004. Behaviour of posttensioned concrete box girders. Proc ICE Bridge Eng 2004; 157(BE2):71-81.

Maisel, B. I., 1970. Review of literature related to the analysis and design of thin-walled beams. Tech. Rep. No. 42440, Cement and Concrete Association, London.

Maisel, B. I., Rowe, R. E., Swann, R. A. 1973. Concrete box girder bridges, The Structural Engineer, 51(10), 363-376.

Mander, J., Priestley, M. J. N., Park, R., 1998. Theoretical Stress-Strain Model for Confined Concrete. Journal of Structural Engineering, 114(8), pp. 1804-1826.
Mircea, C. G. R, Ioani, A., Kiss, Z., (2009). Full scale test on a bridge PC box girder, ISEC-5 The Fifth International Structural Engineering and Construction Conference, September 21-27, 2009, Las Vegas, NV, USA.

Păstrav, M., (2011). Testing on a Prestressed Beam U 37m. Urbanism. Architecture. Construction. Vol. 1, nr. 2, http://uac.incd.ro/Art/v2n1a04.pdf. (Stand Pentru Încercarea Grinzilor Precomprimate $U 37 \mathrm{~m}$, Urbanism. Arhitectură. Construcții Vol. 1, nr. 2, http://uac.incd.ro/Art/v2n1a04.pdf.)

Ramos, O. R., Schanack , F., Ortega, G., Pantaleón, M. J., (2010). Unusual structural effects in a variable-depth box girder bridge: The Pujayo viaduct, Elsevier, Engineering Structures 33 (2011) 615-620.

** Report about Beam Girder Bridge nr. 96/41, Contract 1167/2008: Tests on Prestressed Girder Nr. 96-41, Cluj-Napoca INCERC (Referat cu privire la încercarea Grinzii de pod $n r$. 96/41, Contract 1167/2008: Încercarea Grinzii Precomprimate Nr. 96-41, INCERC Cluj-Napoca).

Robertson I. N., 2005. Prediction of vertical deflections for a long-span prestressed concrete bridge structure, Department of Civil and Environmental Engineering, University of Hawaii, Honolulu, HI 96822, USA, 1 July 2005.

Stratford, T. J., Burgoyne, C. J., and Taylor, H.P.J., 1999. The stability design of long, precast concrete beams. Proc. CE, 119, Part 2, pp. 159-168.

Sennah, K. M., Kennedy, J. B., 2002. Literature review in analysis of box-girder bridges. Journal of Bridge Engineering, ASCE 2002; 7:134.

Zhi-Qi He, Liu Z., (2010). Optimal three-dimensional strutand-tie models for anchorage diaphragms in externally prestressed bridges, Elsevier, Engineering Structures 32 (2010) 2057_2064. 